\title{
原著
}

\section{飼料中のカルシウム含量が妊娠白ネズミのカルシウ \\ ム, リンおよびマグネシウム代謝におよぼす影響 \\ The Effect of Calcium Level of Diet on the Metabolism of \\ Calcium, Phosphorus and Magnesium in Pregnant Rats}

\section{第 1 報 妊娠白ネズミの無機質代謝}

\section{Part 1 Mineral Metabolism in Pregnant Rats}

金沢大学医学部衛生学教室 (Department of Hygiene, School of Medicine, Kanazawa University)

関

博 麿 (Hiromaro Seki)

Metabolism of calcium, phosphorus and magnesium during pregnancy was investigated with 20 primigravida albino rats about $170 \mathrm{~g}$ body weight of Wister Imamichi strain fed with diets containing Ca 0.534 and $1.077 \%$ respectively.

The animals were divided into four groups (A, B, C and D), and in the early period of pregnancy, $\mathrm{A}$ and $\mathrm{B}$ group were fed with low-Ca diet and $\mathrm{C}$ and $\mathrm{D}$ group were fed high-Ca diet. In the middle period, $\mathrm{A}$ and $\mathrm{D}$ group fed with low, and $\mathrm{B}$ and $\mathrm{C}$ group with high, then in the last period $\mathrm{A}$ and $\mathrm{B}$ fed with high, and $\mathrm{C}$ and $\mathrm{D}$ with low $\mathrm{Ca}$ diet.

In the early period, calcium retention increased with the amount of calcium intake, therefore the absorption and the utilization of calcium were better in high calcium groups. In the middle and last period, the absorption rate was decreased and the amount of calcium retention of group $\mathrm{C}$ was smaller than that of calcium requirement for growth of fetuses.

It seemed that the calcium need to fetuses was removed from the calcium stored in mother rat during the early period of pregnancy.

From these results, it is considered that high calcium feeding in the middle or in the last period of pregnancy have no effect on calcium utilization, therefore it is preferable to feed high calcium diet from the beginning of pregnancy.

Absorption and utilization of phosphorus in diet are affected by it $\mathrm{Ca} / \mathrm{P}$ ratio, and the rats of high-Ca group utilized $\mathrm{P}$ better than that of the low-Ca grodp

Metabolism of magnesium resembles to that of phosphorus, and high $\mathrm{Ca} / \mathrm{Mg}$ ratio in diet seems to have good effect on magnesium utilization.

妊娠時のカルシウム代謝は母体の平衡維持と胎仔の骨形成に必要な量を満たさなければならず，母体におけ るとれらの代謝は非妊時とはまた異なる様相を示し, 胎仔のカルシウム（以下 Ca とす）要求量の增大と親の $\mathrm{Ca}$ 吸収率，蓄積量との間に平行関係はないといえる1)。このことは非常に重要な問題なので，初妊白ネズミ に Ca 含量が異なる飼料を妊娠期と各種に組み合わせて投与し， Ca の効果的な投与方法を知るため出納実験

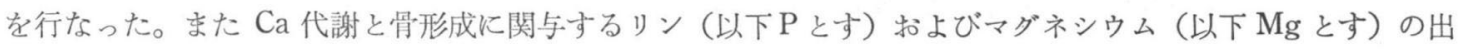
納観察も併せて行なった。 


\section{実 験 方 法}

妊娠経験のない体重 $170 \mathrm{~g}$ 前後のウイスター今道の白ネズミを用いた。

表 1 飼料組成

\begin{tabular}{|c|c|}
\hline ブドウ糖 & $36.0 \%$ \\
\hline デン粉 & 32.9 \\
\hline カゼイン & 20.0 \\
\hline 大豆油 & 5.0 \\
\hline 無機塩類 ${ }^{1)}$ & 5.0 \\
\hline ビタミン混合1) & 1.0 \\
\hline 塩化コリン & 0.1 \\
\hline
\end{tabular}

表 2 妊娠各期に投与した飼料

\begin{tabular}{ccccc}
\hline 動 物 群 & $\mathrm{A}$ & $\mathrm{B}$ & $\mathrm{C}$ & $\mathrm{D}$ \\
\hline 妊 娠 初 期 & 低 $\mathrm{Ca}$ 食 & 低 $\mathrm{Ca}$ 食 & 高 $\mathrm{Ca}$ 食 & 高 $\mathrm{Ca}$ 食 \\
妊 娠 中 期 & 低 $\mathrm{Ca}$ 食 & 高 $\mathrm{Ca}$ 食 & 高 $\mathrm{Ca}$ 食 & 低 $\mathrm{Ca}$ 食 \\
妊 娠 後期 & 高 $\mathrm{Ca}$ 食 & 高 $\mathrm{Ca}$ 食 & 低 $\mathrm{Ca}$ 食 & 低 $\mathrm{Ca}$ 食 \\
\hline 低 $\mathrm{Ca}$ 食: $\mathrm{Ca} 534 \mathrm{mg} \%, \mathrm{P} 650 \mathrm{mg} \%, \mathrm{Mg} 71 \mathrm{mg} \%, \mathrm{Ca} / \mathrm{P}$ 比 0.82 \\
高 $\mathrm{Ca}$ 食: $\mathrm{Ca} 1077 \mathrm{mg} \%, \mathrm{P} 650 \mathrm{mg} \%, \mathrm{Mg} 86 \mathrm{mg} \%, \mathrm{Ca} / \mathrm{P}$ 比 1.66
\end{tabular}

飼料組成を表 1 に示す。飼料中の無機質量は調整後に分析したもので, 第 1 飼料は Ca 量 $534 \mathrm{mg} \%$ で以下 便宜上低 $\mathrm{Ca}$ 食とし，第 2 飼料は $\mathrm{Ca}$ 量 $1077 \mathrm{mg} \%$ で以下高 $\mathrm{Ca}$ 食とす。白ネズミを40匹用意し, 低 $\mathrm{Ca}$ 食を 5 日間投与して環境にならさせたのち交配させ，妊娠を確認したものから順に $\mathrm{A}, \mathrm{B}, \mathrm{C}$ 拈よび $\mathrm{D}$ の 4 群に分け 1 群を 5 匹とし，全期間を初期，中期㧍よび後期に分け，1期間を 7 日間とし後期は分婏までとしないで，妊 娠22日目の朝で出納観察を終った。期間中の飼料投与順序は表 2 のごとくで, 飼有方法, 飼料投与方法, 屎 . 尿採取法，妊娠確認法および無機質定量法はすべて前報1)と扣なじである。

表 3 食料摂取量と体重增の 1 日当りの平均値

\begin{tabular}{|c|c|c|c|c|c|c|}
\hline 動 & 物 & 群 & A & B & C & $\mathrm{D}$ \\
\hline \multirow{3}{*}{ 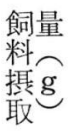 } & 妊 娠 & 期 & $15.5 \pm 0.9$ & $14.7 \pm 0.5$ & $14.2 \pm 0.4$ & 14. $9 \pm 1.1$ \\
\hline & & 中 期 & 17. $2 \pm 0.7$ & $17.3 \pm 0.3$ & $17.1 \pm 0.5$ & $15.4 \pm 0.8$ \\
\hline & & 後 期 & $16.1 \pm 0.5$ & $16.6 \pm 0.9$ & $16.0 \pm 0.3$ & $14.6 \pm 0.5$ \\
\hline 体 & 妊 娠 & 初 期 & $2.3 \pm 0.5$ & $2.3 \pm 0.4$ & $2.5 \pm 0.3$ & $3.6 \pm 0.5$ \\
\hline 重万 & & 中 期 & 3. $3 \pm 0.3$ & 4. $6 \pm 0.1$ & 4. $9 \pm 0.1$ & $3.2 \pm 0.4$ \\
\hline 增量 & & 後 期 & $7.7 \pm 0.5$ & $8.3 \pm 0.7$ & $7.8 \pm 0.5$ & $6.7 \pm 0.6$ \\
\hline
\end{tabular}

各群 5 匹の平均值士標準誤差

\section{実験結果亡考察}

$\mathrm{Ca}$ 出納を表 4 亿示す。初期に $\mathrm{Ca}$ 含量が同一の飼料を投与したにもかかわらず， $\mathrm{A}$ 群と $\mathrm{B}$ 群（低 $\mathrm{Ca}$ 食群） の間に, また $\mathrm{C}$ 群と $\mathrm{D}$ 群（高 $\mathrm{Ca}$ 食群）の間にも吸収率，蓄積量に差がみられたが，これを低 $\mathrm{Ca}$ 食群と高 $\mathrm{Ca}$ 食群の 2 群に分けて観察すると吸収率は低 $\mathrm{Ca}$ 食群 $21.2 \%$, 高 $\mathrm{Ca}$ 食群 $20.2 \%$ で両群の間にあまり差はないが, 蓄積量は低 $\mathrm{Ca}$ 食群 $16.0 \mathrm{mg} /$ 日, 高 $\mathrm{Ca}$ 食群 $30.5 \mathrm{mg}$ / 日で明らかに有意の差がある。妊娠初期に Ca を 846

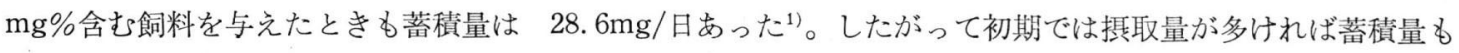
多いようで，投与量の多少にかかわらず吸収率が近似であれば初期に高 $\mathrm{Ca}$ 食を投与した方が $\mathrm{Ca}$ を蓄積する には有効である。胎仔がその形を備光骨形成が盛んになるのは, 妊娠14日以降の後期であるから ${ }^{1)}$ 初期に親が 摂取した Ca は親の体内に貯留されたものと考えてよい。

中期に初期と括なじ飼料を投与した $\mathrm{A}$ 群（低 $\mathrm{Ca}$ 食）の吸収率は $22.7 \% ， \mathrm{C}$ 群（高 $\mathrm{Ca}$ 食）は16.3\%と低い が，蓄積量は $\mathrm{A}$ 群 $(19.8 \mathrm{mg} /$ 日) より C 群 $(28.9 \mathrm{mg} /$ 日) の方が多い。高 $\mathrm{Ca}$ 食を投与した $\mathrm{B}$ 群は吸収率 $(23.3$ 
表 4 妊娠時に抢けるカルシウム出納 $(\mathrm{mg} /$ 匹/日)

\begin{tabular}{|c|c|c|c|c|c|}
\hline 動 & 物 & A & B & $\mathrm{C}$ & $\mathrm{D}$ \\
\hline & 捸 取 量 & $81.9 \pm 4.7$ & $76.5 \pm 2.5$ & $152.5 \pm 4.1$ & $157.9 \pm 12.5$ \\
\hline 妊 & 屎中排泄量 & $68.4 \pm 3.8$ & $56.2 \pm 1.8$ & $124.4 \pm 4.6$ & $123.0 \pm 9.7$ \\
\hline \multirow{2}{*}{ 娠 } & 尿中排泄量 & $0.9 \pm 0.1$ & 1. $0 \pm 0.1$ & $1.1 \pm 0.2$ & $1.1 \pm 0.2$ \\
\hline & 吸 収 量 & $13.5 \pm 3.4$ & $20.3 \pm 2.2$ & $28.1 \pm 2.1$ & $34.9 \pm 4.1$ \\
\hline 初 & 吸 収 率 $(\%)$ & $(16.1 \pm 3.6)$ & $(26.4 \pm 2.3)$ & $(18.5 \pm 1.4)$ & $(22.0 \pm 1.9)$ \\
\hline \multirow[t]{3}{*}{ 期 } & 蓄，積 量 & $12.6 \pm 3.5$ & 19. $3 \pm 2.2$ & $27.0 \pm 2.0$ & $33.9 \pm 4.1$ \\
\hline & 蓄 積 率(\%) & $(15.0 \pm 3.8)$ & $(25.1 \pm 2.3)$ & $(17.8 \pm 1.4)$ & $(21.4 \pm 2.0)$ \\
\hline & 摂 取 量 & $90.9 \pm 4.2$ & $186.0 \pm 2.8$ & $184.0 \pm 5.0$ & $78.0 \pm 3.3$ \\
\hline 妊 & 屎中排泄量 & $70.1 \pm 2.1$ & $142.6 \pm 3.1$ & $154.0 \pm 5.1$ & $68.4 \pm 3.8$ \\
\hline \multirow{2}{*}{ 娠 } & 尿中排泄量 & $1.0 \pm 0.2$ & $1.5 \pm 0.3$ & $1.1 \pm 0.4$ & $1.0 \pm 0.2$ \\
\hline & 吸 収 量 & $20.8 \pm 2.4$ & $43.4 \pm 1.1$ & $30.0 \pm 3.0$ & $9.5 \pm 1.7$ \\
\hline 中 & 吸 収 率(\%) & $(22.7 \pm 1.6)$ & $(23.3 \pm 0.7)$ & $(16.3 \pm 1.5)$ & $(12.3 \pm 2.3)$ \\
\hline \multirow[t]{3}{*}{ 期 } & 蓄 積 量 & $19.8 \pm 2.4$ & $41.9 \pm 1.0$ & $28.9 \pm 2.8$ & $8.5 \pm 1.9$ \\
\hline & 蓄 積 率(\%) & $(21.6 \pm 1.0)$ & $(22.6 \pm 0.7)$ & $(15.7 \pm 1.4)$ & $(11.0 \pm 2.5)$ \\
\hline & 摂 取 量 & $173.6 \pm 5.2$ & $178.7 \pm 9.4$ & $85.4 \pm 1.7$ & $74.0 \pm 2.8$ \\
\hline \multirow{3}{*}{$\begin{array}{l}\text { 妊 } \\
\text { 娠 }\end{array}$} & 屎中排泄量 & $144.5 \pm 11.5$ & $158.2 \pm 7.7$ & $70.3 \pm 1.5$ & $55.4 \pm 2.2$ \\
\hline & 尿中排泄量 & $1.3 \pm 0.2$ & $1.1 \pm 0.04$ & $0.9 \pm 0.2$ & $0.9 \pm 0.1$ \\
\hline & 吸 収 量 & $29.2 \pm 10.7$ & $20.5 \pm 5.3$ & $15.1 \pm 2.2$ & $18.6 \pm 1.5$ \\
\hline 後 & 吸 収 率(\%) & $(16.8 \pm 6.0)$ & $(11.4 \pm 2.9)$ & $(17.6 \pm 2.3)$ & $(25.1 \pm 1.5)$ \\
\hline \multirow[t]{2}{*}{ 期 } & 蓄 積 量 & $27.9 \pm 10.7$ & $19.4 \pm 6.5$ & $14.3 \pm 2.2$ & $17.7 \pm 1.5$ \\
\hline & 蓄 積 率(\%) & $(16.1 \pm 6.1)$ & $(10.7 \pm 3.0)$ & $(16.6 \pm 2.3)$ & $(23.9 \pm 1.5)$ \\
\hline
\end{tabular}

各群 5 匹の平均值士標準誤差

\%)が低下したが蓄積量は他の群より多く $41.9 \mathrm{mg} /$ 日もあり，蓄積率も $22.6 \%$ と高かった。低 $\mathrm{Ca}$ 食の $\mathrm{D}$ 群は （投与方法としては適当ではない）吸収量, 蓄積量ともに他の 3 群より劣って, 初期よりすべてが激減した。 これは初期に高 $\mathrm{Ca}$ 食であったため, 中期になった直後の屎中排泄には高 $\mathrm{Ca}$ 食慨の屎の残りが出たものと思 われるので， $\mathrm{D}$ 群中期の数值は摂取量の低下によるものとは断定できない。中期における胎仔はまだ $\mathrm{Ca}$ 要求 量が多くない1)ので，親が摂取した Ca は初期と抽なじく体内に貯留されていると推定してよい。

後期は胎仔の $\mathrm{Ca}$ 要求量が急速に增大する時期なので, 親の $\mathrm{Ca}$ 吸収率, 蓄積量も当然增加すると考兄られ ていたが， A，B群（高 $\mathrm{Ca}$ 食）の吸収率は中期より低下し，とくにB群は吸収量（率）および蓄積量（率） ともに中期の $1 / 2$ に激減した。西村 ${ }^{2)}$ による妊婦の Ca 吸収率は 29 週では $24.2 \%, 33$ 週では摂取量 $915 \mathrm{mg}(1$ 日平均）に対して17.3\%と低下し，他の期間でる Ca 摂取量が多い場合に必ずしも吸収率は上年していないし， 少ない場合でも高率に吸収されず，妊娠後半では親の吸収利用は低下する。

胎仔の $\mathrm{Ca}$ 要求量が増大するまでにどの位の $\mathrm{Ca}$ 蓄積があったら妥当かは判明しないが, 各群の蓄積は $\mathrm{A}$ 群 初期88.3mg, 中期 138.4mg，B群初期 135.2mg, 中期 293.3mg，C群初期 189.1mg, 中期 $202.2 \mathrm{mg}$, 飼 料投与方法が悪いと思われた D 群は初期 $237.2 \mathrm{mg}$, 中期 $59.6 \mathrm{mg}$ で $\mathrm{A}$ 群よりも蓄積量が多いことは注目すべ きことである。初・中期では胎仔の $\mathrm{Ca}$ 要求量が少ない1)のでこれらの量は多分に親の体内にプールされたと 思われるし，吸収率もそれほど悪くはないので，初・中期のうちいずれかの時期に高 $\mathrm{Ca}$ 食を投与する方が親 の $\mathrm{Ca}$ 代謝からみて有效なようである。 
表 5 妊娠時に括けるリン出納 $(\mathrm{mg} /$ 匹/日)

\begin{tabular}{|c|c|c|c|c|c|}
\hline 動 & 群 & A & $\mathrm{B}$ & $\mathrm{C}$ & $\mathrm{D}$ \\
\hline & 摂 取 量 & $101.8 \pm 6.0$ & $96.3 \pm 3.3$ & $91.3 \pm 2.4$ & $94.6 \pm 7.5$ \\
\hline 妊 & 屎中排泄量 & $52.5 \pm 3.7$ & 44. $0 \pm 2.1$ & $61.3 \pm 2.4$ & $54.1 \pm 5.6$ \\
\hline \multirow{2}{*}{ 娠 } & 尿中排泄量 & $30.6 \pm 2.4$ & $27.7 \pm 0.7$ & 11. $3 \pm 0.9$ & $13.1 \pm 0.5$ \\
\hline & 吸 収 量 & $49.3 \pm 5.3$ & $52.3 \pm 2.4$ & $30.0 \pm 1.0$ & 40. $4 \pm 1.9$ \\
\hline 初 & 吸 収 率(\%) & $(48.1 \pm 3.3)$ & $(54.3 \pm 1.7)$ & $(32.9 \pm 1.2)$ & $(43.2 \pm 1.5)$ \\
\hline \multirow[t]{3}{*}{ 期 } & 蓄 積 量 & $8.6 \pm 4.6$ & $24.5 \pm 2.6$ & $18.6 \pm 0.6$ & $27.4 \pm 1.8$ \\
\hline & 蓄＼cjkstart積＼cjkstart率(\%) & $(17.9 \pm 4.0)$ & $(25.4 \pm 2.3)$ & $(20.5 \pm 1.1)$ & $(29.1 \pm 1.0)$ \\
\hline & 蓄積量のCa/P比 & $0.69 \pm 0.14$ & $0.82 \pm 0.12$ & 1. $45 \pm 0.12$ & $1.22 \pm 0.09$ \\
\hline \multirow{3}{*}{ 妊 } & 摂 取 量 & $112.9 \pm 4.9$ & 111. $4 \pm 1.7$ & $110.2 \pm 3.0$ & $100.9 \pm 5.1$ \\
\hline & 屎中排泄量 & $51.5 \pm 2.6$ & $65.9 \pm 1.8$ & $73.3 \pm 6.0$ & $47.0 \pm 3.5$ \\
\hline & 尿中排泄量 & $33.6 \pm 2.6$ & $14.8 \pm 1.4$ & $14.3 \pm 0.6$ & 31. $2 \pm 1.2$ \\
\hline \multirow{3}{*}{$\begin{array}{l}\text { 娠 } \\
\text { 中 }\end{array}$} & 吸 収 量 & $61.4 \pm 3.4$ & $45.5 \pm 1.4$ & $36.9 \pm 3.8$ & $53.9 \pm 2.3$ \\
\hline & 吸 収 率 $(\%)$ & $(54.4 \pm 1.6)$ & $(40.9 \pm 1.2)$ & $(33.8 \pm 3.9)$ & $(53.6 \pm 1.6)$ \\
\hline & 蓄 積 量 & $27.8 \pm 1.7$ & $30.7 \pm 1.4$ & $22.5 \pm 4.3$ & $22.7 \pm 1.7$ \\
\hline \multirow[t]{2}{*}{ 期 } & 蓄 積 率(\%) & $(24.7 \pm 1.6)$ & $(27.6 \pm 1.5)$ & $(20.7 \pm 4.1)$ & $(22.5 \pm 1.6)$ \\
\hline & 蓄積量の $\mathrm{Ca} / \mathrm{P}$ 比 & $0.68 \pm 0.08$ & $1.38 \pm 0.05$ & 1. $68 \pm 0.62$ & $0.36 \pm 0.06$ \\
\hline \multirow[b]{3}{*}{ 妊 } & 摂 取 量 & $104.0 \pm 3.2$ & $107.0 \pm 5.6$ & 104. $7 \pm 2.2$ & $95.6 \pm 3.3$ \\
\hline & 屎中排泄量 & $63.3 \pm 4.3$ & $68.2 \pm 4.1$ & 48. $4 \pm 1.3$ & 41. $6 \pm 2.6$ \\
\hline & 尿中排泄量 & $12.4 \pm 0.5$ & $10.8 \pm 0.9$ & 28. $0 \pm 1.1$ & $24.9 \pm 1.7$ \\
\hline 娠 & 吸 収 量 & $40.7 \pm 4.5$ & $38.8 \pm 4.6$ & $56.3 \pm 1.9$ & $54.0 \pm 3.1$ \\
\hline \multirow{4}{*}{$\begin{array}{l}\text { 後 } \\
\text { 期 }\end{array}$} & 吸 収 率 $(\%)$ & $(39.1 \pm 4.0)$ & $(35.9 \pm 3.6)$ & $(53.7 \pm 1.2)$ & $(56.5 \pm 2.3)$ \\
\hline & 蓄 積 量 & $28.3 \pm 4.3$ & $28.0 \pm 4.3$ & $28.3 \pm 1.4$ & $29.1 \pm 1.6$ \\
\hline & 蓄 積 率(\%) & $(27.0 \pm 3.9)$ & $(25.8 \pm 3.6)$ & $(27.0 \pm 1.0)$ & $(30.4 \pm 1.1)$ \\
\hline & 蓄積量の $\mathrm{Ca} / \mathrm{P}$ 比 & $0.89 \pm 0.02$ & $0.64 \pm 0.11$ & $0.50 \pm 0.06$ & $0.61 \pm 0.05$ \\
\hline
\end{tabular}

各群 5 匹の平均值士標準誤差

後期に括ける 1 腹の胎仔の $\mathrm{Ca}$ 要求量 ${ }^{3)}$ と親自身の $\mathrm{Ca}$ 出納量との関係は, $\mathrm{A}$ 群の胎仔の $\mathrm{Ca}$ 要求量は 100.9 $\mathrm{mg}$, 蓄積量 $195.0 \mathrm{mg}$ でこの差を親の蓄積とすると+94.1mg, B 群は要求量 $127.3 \mathrm{mg}$, 蓄積量 $135.5 \mathrm{mg}$ で+8.2 $\mathrm{mg}$, C群は要求量 $109.9 \mathrm{mg}$, 蓄積量 $99.9 \mathrm{mg}$ で $-10.0 \mathrm{mg}$, D 群は要求量 D104.0mg, 蓄積量 $124.2 \mathrm{mg}$ で +20.2mg となり，ここでも注目すべきことは条件の悪いD群が $+20.2 \mathrm{mg}$ の蓄積があったことである。

胎仔の骨形成に動員される Ca は食飳性 Ca のみに由来するものでないことは, 胎仔の Ca 要求量が增大す る後期に拈ける $\mathrm{Ca}$ 吸収率, 蓄積量の低下から, また前報”の結果からもいえる。もし胎仔の骨形成に動員さ れる $\mathrm{Ca}$ が, 食餉性 $\mathrm{Ca}$ のみによるものとすれば, 後期に高 $\mathrm{Ca}$ 食を投与した $\mathrm{A} ・ \mathrm{~B}$ 両群の吸収率, 蓄積率は 増大すべきであるのにかえって中期より低下しているのは骨形成に動員される Ca は, 食慨性 Ca 以外のもの が動員されていることを意味している。

妊娠後期に $\mathrm{Ca}$ を補給投与することは必要ではめるが, A ・ B 両群の蓄積量を見るとA群 $27.9 \mathrm{mg} /$ 日, B群 19. $4 \mathrm{mg}$ /日で A 群の方が勝って効果的には見えるが，分散が大きく，つまりばらつきが多いので適当なCa投 与方法とはいえない。以上のことから妊娠時に Ca 投与量を增す時期は後期では㧍そく, 飼料に対する適応性 と母体の蓄積を考虑して中期には投与量を增加すべきで, できれば妊娠初期から多くの Ca を投与することが 望ましい。 
$\mathrm{P}$ 出納を表 5 に示す。飼料中の $\mathrm{P}$ 含量は全期間を通じて同一であるにもかかわらず, 各群間の出納は拉なじ 傾向ではなく，低Ca 食群と高Ca 食群の間にはっきりとした差が認められた。全期間を通じてい光ることは低 $\mathrm{Ca}$ 食群は高 $\mathrm{Ca}$ 食群より屎中排泄が少なく，尿中排泄が多い。したがって吸収率が高い。初期の蓄積量につ いては $\mathrm{Ca}$ と执なじく $\mathrm{A} ・ \mathrm{~B}$ 群の間に，また C ・ D 群の間にも差があったが，低 $\mathrm{Ca}$ 食群，高 $\mathrm{Ca}$ 食群の間に はあまり差がない。胎仔の $\mathrm{P}$ 要求量は $\mathrm{Ca}$ と同じく後期に增大するが, 1 腹の要求量 ${ }^{3}$ は $\mathrm{A}$ 群 $122.1 \mathrm{mg}, \mathrm{B}$ 群 148.3mg, C 群127.7mg 拈よびD群 121.9mgで, これに対して各群後期の蓄積量は A 群198.0mg, B群195.7 $\mathrm{mg}, \mathrm{C}$ 群198.2mg, 飼料条件の悪いD 群が $203.8 \mathrm{mg}$ で, いずれも胎仔の P 要求を満足して $\mathrm{Goss}^{4)}$, Sherman ${ }^{5)}$ らのごとく脱 $\mathrm{P}$ 起していない。

飼料中の $\mathrm{Ca} / \mathrm{P}$ 比は非妊時の $\mathrm{Ca}, \mathrm{P}$ 出納に影響があるが，妊娠時のごとく骨形成のみでなく，体成分にも $\mathrm{P}$ が重要な役割を示す場合は，またこの $\mathrm{Ca} / \mathrm{P}$ 比が $\mathrm{P}$ 出納に重要な因子となっている。 $\mathrm{Ca}$ と $\mathrm{P}$ の吸収利用

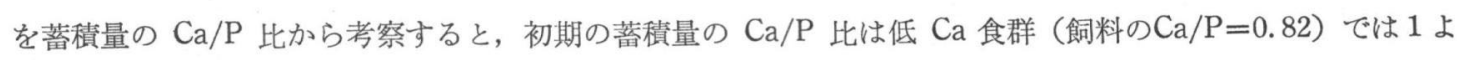
り小であるが，高 $\mathrm{Ca}$ 食群（飼料の $\mathrm{Ca} / \mathrm{P}=1.66$ )では 1 より大で $\mathrm{Ca}$ の利用は良い。 $\mathrm{P}$ は吸収はよいが蓄積量 についてはあまり差がない。中期でも低 $\mathrm{Ca}$ 食群は 1 より小で, 高 $\mathrm{Ca}$ 食群は 1 より大である。後期に拈いて は, いずれの群も 1 より小となり,この $\mathrm{Ca} / \mathrm{P}$ 比からも初・中期での $\mathrm{Ca}$ の利用が後期よりもよいこと, また $\mathrm{P}$ は $\mathrm{Ca}$ と異なる代謝をすることを示している。

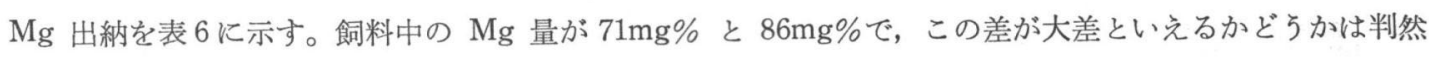
表 6 妊娠時に叔けるマダネシウム出納 $(\mathrm{mg} /$ 匹/日)

\begin{tabular}{|c|c|c|c|c|c|c|}
\hline 動 & 物 & 群 & A & B & $\mathrm{C}$ & D \\
\hline & 摂 取 最 & & $11.9 \pm 0.9$ & $10.7 \pm 0.7$ & $12.2 \pm 0.3$ & $12.6 \pm 1.0$ \\
\hline 妊 & 尿中排泄最 & & $5.1 \pm 0.2$ & $3.9 \pm 0.4$ & $5.0 \pm 0.4$ & $4.7 \pm 0.6$ \\
\hline \multirow{2}{*}{ 娠 } & 尿中排泄㝵 & & $3.5 \pm 0.4$ & $3.8 \pm 0.2$ & $2.7 \pm 0.2$ & 3. $1 \pm 0.3$ \\
\hline & 吸収 旦 & 量 & $6.9 \pm 0.7$ & $6.9 \pm 0.7$ & $7.2 \pm 0.2$ & $7.9 \pm 0.6$ \\
\hline 初 & 吸収 & 率(\%) & $(57.2 \pm 2.9)$ & $(63.6 \pm 4.1)$ & $(59.5 \pm 2.4)$ & $(63.0 \pm 2.8)$ \\
\hline \multirow[t]{2}{*}{ 期 } & 蓄 積 旦 & 量 & 3. $4 \pm 0.8$ & $3.1 \pm 0.6$ & 4. $6 \pm 0.3$ & $4.8 \pm 0.4$ \\
\hline & 蓄 積 & 率(\%) & $(27.4 \pm 0.5)$ & $(28.1 \pm 4.2)$ & $(37.8 \pm 3.1)$ & $(38.3 \pm 2.8)$ \\
\hline \multirow{5}{*}{$\begin{array}{l}\text { 妊 } \\
\text { 娠 } \\
\text { 中 }\end{array}$} & 摂 取 最 & & 13. $3 \pm 1.0$ & $14.9 \pm 0.2$ & $14.7 \pm 0.4$ & $9.9 \pm 0.3$ \\
\hline & 屎中排泄㝵 & & $5.3 \pm 0.4$ & $5.8 \pm 0.6$ & $5.9 \pm 0.2$ & $4.5 \pm 0.4$ \\
\hline & 尿中排泄量 & & $3.6 \pm 0.4$ & $4.0 \pm 0.2$ & $3.1 \pm 0.2$ & $3.7 \pm 0.2$ \\
\hline & 吸 収 量 & 量 & $8.0 \pm 0.7$ & 9. $1 \pm 0.6$ & $8.9 \pm 0.4$ & $5.5 \pm 0.4$ \\
\hline & 吸 収 & 率(\%) & $(59.6 \pm 1.4)$ & $(60.9 \pm 3.8)$ & $(60.1 \pm 1.5)$ & $(55.4 \pm 3.5)$ \\
\hline \multirow[t]{3}{*}{ 期 } & 蓄 積 量 & 量 & $4.3 \pm 0.6$ & $5.1 \pm 0.5$ & $5.8 \pm 0.2$ & $1.8 \pm 0.5$ \\
\hline & 蓄 積 & 率(\%) & $(31.7 \pm 2.5)$ & $(34.4 \pm 3.7)$ & $(39.3 \pm 1.1)$ & $(17.8 \pm 4.7)$ \\
\hline & 摂!取 量 & 量 & $13.9 \pm 0.4$ & $14.3 \pm 0.8$ & 13. $0 \pm 0.3$ & $9.6 \pm 0.7$ \\
\hline \multirow{3}{*}{$\begin{array}{l}\text { 娃 } \\
\text { 娠 }\end{array}$} & 屎中排泄量 & 量 & $5.2 \pm 0.3$ & $5.9 \pm 0.3$ & $4.4 \pm 0.2$ & $3.5 \pm 0.4$ \\
\hline & 尿中排泄量 & 量 & $2.9 \pm 0.2$ & $2.9 \pm 0.1$ & $3.4 \pm 0.3$ & $3.4 \pm 0.2$ \\
\hline & 吸 収 量 & 量 & $8.7 \pm 0.5$ & $8.4 \pm 0.6$ & $8.6 \pm 0.3$ & $5.8 \pm 0.8$ \\
\hline 後 & 吸 収 & 率(\%) & $(62.6 \pm 2.4)$ & $(58.3 \pm 2.0)$ & $(66.4 \pm 2.1)$ & $(60.2 \pm 4.2)$ \\
\hline \multirow[t]{2}{*}{ 期 } & 蓄 積 & 量 & $5.8 \pm 0.4$ & $5.5 \pm 0.6$ & $5.2 \pm 0.1$ & $2.4 \pm 0.6$ \\
\hline & 蓄 積 & 率(\%) & $(41.7 \pm 2.6)$ & $(37.9 \pm 2.4)$ & $(40.1 \pm 0.9)$ & $(24.0 \pm 4.3)$ \\
\hline
\end{tabular}

各群 5 匹の平均值士標準誤差 
としないが，低 $\mathrm{Ca}$ 食群と高 $\mathrm{Ca}$ 食群の間に蓄積量にわずかながら差がみられたが，Mgについては Ca およ び $\mathrm{P}$ と異なり攝取量も少ないので， $1 \mathrm{mg}$ 内外の差が大きな意味があるかどうかは今後検討したいが, $\mathrm{D}$ 群の蓄 積量は中・後期とも他の 3 群より劣っていた。Coons ${ }^{6)}$ らが食慨中の $\mathrm{Ca} / \mathrm{Mg}$ 比が $1.5 \sim 4.7$ と食慨をとった 妊婦の $\mathrm{Ca}$ 蓄積はあまり効果的でなく，Mg 自体の蓄積でも23例中12例が負出納を示していたが，本実験では $\mathrm{Ca} / \mathrm{Mg}$ 比が 7.52 と $12.52 て ゙$ Coons らよりも比が高かったためか負出納の親はいない。後期の蓄積量は $\mathrm{A}$ 群 $40.7 \mathrm{mg}, \mathrm{B}$ 群 $38.3 \mathrm{mg}, \mathrm{C}$ 群 $36.0 \mathrm{mg}$ 占よび $\mathrm{D}$ 群 $16.5 \mathrm{mg}$ でばらつきは大きいが， 1 腹の仔の要求量 ${ }^{3)}$ は 8.3 〜 10.8mg で, いずれも親の蓄積量以下であった。 $\mathrm{Mg}$ はCaおよび $\mathrm{P}$ と異なり胎仔の要求量も少なく, 本実験 程度の $\mathrm{Mg}$ 量では親は負出納にはならなかった。

以上のことから飼料中の $\mathrm{Ca}, \mathrm{P}$ 扎よび $\mathrm{Mg}$ の量的比が相互の出納に影響を拉よぼすので, 妊娠初期から高 $\mathrm{Ca}$ 食を投与した方が $\mathrm{Ca}$ は勿論， $\mathrm{P}$ 扣よび $\mathrm{Mg}$ の蓄積のためにも効果があるといるる。

\section{一要約}

妊娠後期に母体 $\mathrm{Ca}$ の吸収拉よび利用が悪くなるといわれるので, 初妊の白ネズミに Ca 含量が異なる高 $\mathrm{Ca}$ 食と低 $\mathrm{Ca}$ 食の 2 種類の飼料を妊娠各期と組み合わせて投与して出納観察を行ない, 後期に扣ける蓄積量と仔 のCa 要求量から Ca を増量投与するのに有効な時期をたしかめた。

1. 妊娠の中・後期から高 $\mathrm{Ca}$ 食を投与しても後期の吸収率および蓄積率は低下傾向で， あまりょく利用さ れていない。後期に高 $\mathrm{Ca}$ 食を投与した群の親は $\mathrm{Ca}$ 蓄積を示したが，低 $\mathrm{Ca}$ 食の $\mathrm{C}$ 群のみは負出納を示した。 $\mathrm{A}$ 群の蓄積は多かったが分散が大きく, 後期のみの高 $\mathrm{Ca}$ 食の投与は適当ではない。 $\mathrm{Ca}$ 投与量を增す時期は 中期または初期からがよく，後期に入ってからの高 $\mathrm{Ca}$ 食投与ではあまり効果的ではない。また飼料中の $\mathrm{Ca}$ 含量は $1.0 \mathrm{~g} \%$ 位がよいようである。

2. 尿中 $\mathrm{P}$ 排泄は各期とも低 $\mathrm{Ca}$ 食群が高 $\mathrm{Ca}$ 食群より多く, 後期の蓄積量は各群間に差はなく, 蓄積量の $\mathrm{Ca} / \mathrm{P}$ 比も初・中期では高 $\mathrm{Ca}$ 食群が 1 より高く, $\mathrm{Ca}$ がよく吸収利用されているが，後期ではいずれの群も 1 以下になり $\mathrm{P}$ の利用が $\mathrm{Ca}$ より多く, 飼料中の $\mathrm{Ca} / \mathrm{P}$ 比が相互の出納に影響がある。

3. 飼料中の $\mathrm{Ca} / \mathrm{Mg}$ 比が $\mathrm{Mg}$ の出納に影響を招上ぼし, 各期とも高 $\mathrm{Ca}$ 食群が低 $\mathrm{Ca}$ 食群より蓄積量が 多かった。初期のみ高 $\mathrm{Ca}$ 食であった親の $\mathrm{Mg}$ 蓄積量は中・後期に低下した。

稿を終るに当り，終始御懇篤なる御指導と御校閲を賜わった石崎有信教授に心から拝謝する。な扣本研究は 厚生省栄養所要量等策定委員会ミネラル小委員会委員長国立栄養研究所速水泱食品化学部長, 同委員相模女子 大学五島孜教授の研究費によるもので，多大な御便宜と御助言を賜わったことを感謝する。

\section{参 考 文 献}

1) 関 博麿: 栄養と食糧, 第 24 巻投稿中

2 ) 西村和男 : 同誌, 13, 233 (1960)

3 ) 関 博麿: 本誌, 投稿中

4) Goss, H. and Schmidt, C. L. A.: J. Biol. Chem., 86, 417 (1930)

5 ) Sherman, H.C. and Quinn, E. J.: J. Biol. Chem., 67, 667 (1926)

6) Coons, C. M. and Blunt, K.: J. Biol. Chem., 86, 1 (1930)

（受付：昭和 46 年 5 月 10 日） 